\title{
Analysis on the Impact of the Fluctuation of the International Gold Prices on the Chinese Gold Stocks
}

\author{
Jiankang Jin, ${ }^{1}$ Chen Jie, ${ }^{2}$ and Quanda Zhang ${ }^{2}$ \\ ${ }^{1}$ School of Economics \& Management, Northwest University, Xian 710127, China \\ ${ }^{2}$ School of Finance, Zhejiang University of Finance and Economics, Hangzhou 310018, China \\ Correspondence should be addressed to Jiankang Jin; jiankangjin760@126.com
}

Received 14 March 2014; Revised 18 June 2014; Accepted 30 June 2014; Published 21 July 2014

Academic Editor: Fenghua Wen

Copyright (c) 2014 Jiankang Jin et al. This is an open access article distributed under the Creative Commons Attribution License, which permits unrestricted use, distribution, and reproduction in any medium, provided the original work is properly cited.

Five gold stocks in Chinese Shanghai and Shenzhen A-share and Comex gold futures are chosen to form the sample, for the purpose of analysing the impact of the fluctuation of the international gold prices on the gold stocks in Chinese Shanghai and Shenzhen A-share. Using the methods of unit root test, Granger causality test, VAR model, and impulse response function, this paper has analysed the relationship between the price change of the international gold futures and the price fluctuation of gold stocks in Chinese Shanghai and Shenzhen comprehensively. The results suggest the fluctuation of the international gold futures has a strong influence on the domestic futures.

\section{Introduction}

Gold futures are a future contract which chooses the gold as subject, and it is a standardized protocol that the seller and the buyer agree to deal in a specific time in the future based on their agreement. In an efficient market, the gold futures market and spot market, however, will respond to innovation at the same time, and there is no lead-lag relationship between the two markets. Product design, trading mechanism, and different investors are the main differences between the gold futures market and spot market. Because of the great risk when investing in the gold futures, many investors prefer gold stock instead of gold futures to be their first choice. Therefore, it is important to understand the relationship between the gold futures and gold stocks. For many investors, it is rather meaningful to predict the trend of the value of listed gold companies and thus make more accurate price estimate when the trend of the gold futures is analyzed and available. This paper has analyzed the relationship between the price change of the international gold futures and the price fluctuation of gold stocks in Chinese Shanghai and Shenzhen comprehensively. Section 2 gives out a review of the literature on the gold futures research, Section 3 explains the research design and innovation, Section 4 introduces the empirical methods, and Section 5 is the empirical process. The results of this paper are given in the last section.

\section{Review of the Literature}

Both the domestic and foreign scholars have studied the relationship between the gold spot and gold futures from many aspects. Using the methods of correlation analysis, unit root test, cointegration test, and Granger Causality test and impulse response function, Jiaming [1] chooses Chinese gold futures as the research object to study the effectiveness of the gold market in China and the United States, respectively. His research suggests there are noneffective factors in gold futures market, and gold spot price has an unidirectional guide to gold futures. Some scholars have researched the relative content from the market viewpoint, such as $[2,3]$. Based on the impulse response function, variance decomposition in vector autoregression model, cointegration test, and Granger causality test, Zhipeng and Guoyan [4] adopt the daily closing price of gold futures 0806 contract, which is the latest issue due between January 9, 2008, and May 16, 2008, traded in Shanghai futures exchange, to be their research object. With the bivariate EC-EGARCH model built, they study the price relationship between gold futures market and gold spot market in China empirically. The result shows that there is no guide relationship in gold futures market and gold spot market in China, which is caused by the weak efficiency of market information transformation, and the gold futures market is not smooth enough in the early stage of Chinese 
gold futures. Using the autoregressive distributed lag model combined with GARCH models, Di and Jiangming [5] study the dynamic relationship between the price volatility of $\mathrm{New}$ York gold futures and the price volatility of copper futures, zinc futures, and natural rubber futures traded in Shanghai futures exchange to measure the effect of macroeconomic performance on Chinese futures market. They find part of futures has showed the financial attributes and is linked closely with macroeconomic volatility in China. Besides, some scholars have researched the investors' risk preference aspect, such as $[6,7]$, and other scholars have researched risk premium viewpoint, such as [8].

Using the daily data of New York mercantile exchange, Shawky et al. [9] study the dynamic relationship between the futures market price and the spot market price by EGARCH model; they also study the inverse relationship between the two markets by building the vector autoregression (VAR) model. Choosing the data of daily yield of gold and silver between 1982 and 2002 to be the sample, Lucey and Tully [10] study the condition and unconditional mean and variance of daily yield based on the frame of GARCH model. Their research shows that daily average yield cyclical characteristic is not obvious, but the cyclical change characteristic of variance is obvious. Hillier et al. [11] study the function of gold futures in securities market, they find 1976-2004 gold and S\&P500 index are negatively correlated, and the portfolio which contains $5 \%-10 \%$ gold has a better performance than other ones which contain no gold. Lin et al. [12] employ a bivariate GARCH model to examine the dynamic relationship between two gold futures markets. Their results show that the performance of Comex is better than TOCOM. Volatility transmission effects exist in both Comex and TOCOM. While the responses to good news and bad news are symmetrical in TOCOM, they are asymmetric in Comex. Cretien [13] offers information about the importance of gold and silver on futures trades in the USA. The paper states the differences and similarities of both precious metals make them a target for options on trade. It mentions that the futures market for gold and silver produces best measure of how well the country currently is protecting the value of dollar. Based on the smooth transition regression model, Lee and Lin [14] investigate the nonlinear dynamic relationship between USD/yen and gold futures in the commodity exchange. The empirical results show the transition function is a logistic type. Gold is both a hedge and a safe haven for developing countries but not for emerging countries; the relationships between gold and emerging market index are positive.

\section{Research Design}

Through the review of the literature above, we find both domestic and foreign scholars choose the gold spot as the corresponding sample when they investigate the gold futures, and the research theme mostly concentrates on the dynamic relationship between gold futures and gold spot instead of the dynamic relationship of gold futures and stocks. Therefore, this paper is aimed at studying the relationship between gold futures and gold stocks. In this paper, we select the Zhongjin
Gold (600489), which enjoys the fame-China No. 1 gold stock in Shanghai and Shenzhen A-share, the Shandong Gold (600547), which is the No. 2 listed company in Chinese gold industry and its corporation size nearly reaches the level of government, the Zijin Mining (600189), which is among the gold producing corporation in China and is evaluated as "Chinese largest gold mine" by China Gold Association, the Chenzhou Mining (002155), which is one of the domestic top ten gold mine development companies, the Shanghai gold exchange consolidated class member and the provider of standard gold bullion, and the Hengbang Stock (002237), which has the gold output that ranked the forefront of the Chinese gold enterprises. The above five gold stocks form the sample (there are more than five gold stocks in Shanghai and Shenzhen A-share, but after a lot of contrast, we found choosing five stocks is most suitable for presentation, not eight or ten), and the Comex gold futures traded in New York form the future sample.

On the data processing, both the domestic and foreign scholars tend to use the raw data or the raw data in logarithmic in their research. And then they will conduct a series of empirical analyses on this basis. However, in this paper, the daily revenue growth rate is calculated on the basis of daily data in the process of gold stock data, and then the weighted average of 5-daily-revenue growth rate of the stock can be counted, what we get is the daily price volatility of Shanghai and Shenzhen gold stocks (the weighted average of the 5-gold-stock daily growth rate of revenue, the following JPS). On the international gold future data processing, the calculated daily growth rate of Comex gold future prices (following Comex) forms the analytical sample, and the time range of the two sets of data starts from January 1, 2010, to December 31, 2012. Considering the effects of time differences caused by the geographical location (New York in West Area 5 while Beijin in East Area 8), we lag the gold futures data a day, contrast the gold stocks and gold futures, and then delete the day data the two sides stop plate and off plate, and then the data we get have the same timeline of gold stock and futures.

On the empirical analysis, the raw data is transferred to weight percentage data. Based on the unit root test, we find both of the two sets of the data are stationary; thus, we can direct use the methods of Granger causality test, to build the VAR model as well as to do the impulse response functions analysis to determine the correlation between the data.

\section{Research Methods}

4.1. ADF Test. ADF test is an augmented version of the Dickey-Fuller test for a larger and more complicated set of time series models. ADF test consists of the following three models:

$$
\begin{aligned}
& \text { Model 1: } \Delta X_{t}=\delta X_{t-1}+\sum_{i=1}^{m} \beta_{i} \Delta X_{t-i}+\varepsilon_{t} . \\
& \text { Model 2: } \Delta X_{t}=\alpha+\delta X_{t-1}+\sum_{i=1}^{m} \beta_{i} \Delta X_{t-i}+\varepsilon_{t} . \\
& \text { Model 3: } \Delta X_{t}=\alpha+\beta_{t}+\delta X_{t-1}+\sum_{i=1}^{m} \beta_{i} \Delta X_{t-i}+\varepsilon_{t} .
\end{aligned}
$$

In the model, $\Delta X_{t}=X_{t}-X_{t-1}, \Delta$ is the first order difference operation factor and the residual term $\varepsilon_{t}$ is the white noise $\left(\varepsilon_{t}\right.$ is the random item with zero mean, constant 
variance, and no autocorrelation). The null hypothesis of three models above is $\mathrm{H}_{0}: \delta=0$, which means there is a unit root. If the ADF test value exceeds the critical value, the null hypothesis $\mathrm{H}_{0}$ cannot be rejected, which means the time series $\mathrm{X}_{t}$ contains a unit root and it is not stationary.

4.2. Granger Causality Test. For the two variables $X$ and $Y$, Granger causality test requires an estimation of the following regression:

$$
\begin{aligned}
& Y_{t}=\beta_{0}+\sum_{i=1}^{m} \beta_{i} Y_{t-i}+\sum_{i=1}^{m} \alpha_{i} X_{t-i}, \\
& X_{t}=\delta_{0}+\sum_{i=1}^{m} \delta_{i} X_{t-i}+\sum_{i=1}^{m} \lambda_{i} Y_{t-i} .
\end{aligned}
$$

We use the assumption that $X$ is not $Y$ Granger cause as example, which is equal to the assumption that the parameter before the $X$ lag items all equals zero, and we make regression which contains the $X$ lag items and regression which does not contain the $X$ lag items. Using $\mathrm{RSS}_{U}$ to represent the former residual sum of squares and $\mathrm{RSS}_{R}$ to represent the latter residual sum of squares, then calculate the $F$ statistic as follows:

$$
F=\frac{\left(\mathrm{RSS}_{R}-\mathrm{RSS}_{U}\right) / m}{\mathrm{RSS}_{U} /(n-k)} .
$$

In the equation, $m$ is the number of the $X$ lag items, $n$ is the number of sample, and $k$ is the number of the unconstrained regression model parameters to be estimated which may contain constant and other variables. If the calculated $F$ value exceeds the corresponding the critical value $F_{\alpha}(m, n-k)$ under the given significance level $\alpha$, then the null hypothesis will be rejected and the $X$ is the Granger cause of $Y$.

4.3. VAR Model. VAR model is used to predict and analyze interrelated time series and the dynamic effects that the random perturbations have on the variable system. There is no need to specify whether some variables are endogenous or exogenous. Besides, VARs allow the value of a variable to depend on its own lags and the lags of other variables. Models thus offer a structure which may be able to capture more characteristics of the data. VAR model is defined as follows.

If $Y_{t}=\left(y_{1 t}, \ldots, y_{N t}\right)^{T}$ is the $N \times 1$ order time series variable column vector, then the $P$ order VAR model (the following $\operatorname{VAR}(P))$ is as follows:

$$
\begin{aligned}
Y_{t}= & \sum_{i=1}^{P} \prod_{i} Y_{t-i}+U_{t} \\
= & \prod_{1} Y_{t-1}+\prod_{2} Y_{t-2} \cdots+\prod_{P} Y_{t-p} \\
& +U_{t} U_{T} \sim \operatorname{IID}(0, \Omega),
\end{aligned}
$$

where $U_{t}=\left(u_{1 t}, \ldots, u_{N t}\right)^{T}$ is $N \times 1$ order random error column vector, $P$ is the maximum lag order of the model, and $\Omega$ is $N \times N$ order covariance matrix. $\operatorname{VAR}(P)$ model is the equations model which chooses the $t$ period variable $y_{1 t}, y_{2 t}, \ldots, y_{N t}$ as dependent variables and the maximum $P$ order lag variables of dependent variables $y_{1 t}, y_{2 t}, \ldots, y_{N t}$ as independent variables, and the equations models have $N$ equations.

4.4. Impulse Response Function. It is absolutely necessary to do the impulse response function analysis to investigate the dynamic characteristics of the Comex and JPS. What the impulse response function concern is the impact that the dependent variables on each variables, it is used to analyze the effect of the information to the system. By applying a unit shock to the disturbance term of each equation, we can get the impact of unit shocks on VAR system in a period of time. We use VAR (2) model which contains two variables as an example to explain. Set two-variable VAR (2) model as follows:

$$
\begin{aligned}
\left(\begin{array}{c}
\mathrm{GDP}_{t} \\
M_{t}
\end{array}\right)= & \left(\begin{array}{ll}
\alpha_{11} & \alpha_{12} \\
\alpha_{21} & \alpha_{22}
\end{array}\right)\left(\begin{array}{c}
\mathrm{GDP}_{t-1} \\
M_{t-1}
\end{array}\right) \\
& +\left(\begin{array}{ll}
\beta_{11} & \beta_{12} \\
\beta_{21} & \beta_{22}
\end{array}\right)\left(\begin{array}{c}
\mathrm{GDP}_{t-2} \\
M_{t-2}
\end{array}\right)+\left(\begin{array}{l}
\mu_{1 t} \\
\mu_{2 t}
\end{array}\right) .
\end{aligned}
$$

In the above equation, $M$ is the money supply. If the system is subject to some kind of disturbance, making $\mu_{1 t}$ change in one standard deviation, the $\mathrm{GDP}_{t}$ not only change immediately (response), but also influence the value of $M_{t}$ through $\mathrm{GDP}_{t-1}, \mathrm{GDP}_{t-2}$, and it will affect the subsequent value of GDP and $M$ (lag response). Impulse response function describes the response trajectory of the interaction between the variables in the system, showing the entire chain reaction process of how any disturbances affect other variables through model.

\section{The Process of Empirical Study}

5.1. ADF Test. In the aspect of testing the stationary of time series, the ADF test is used in this paper. Table 1 is the ADF test results of both JPS and Comex.

As we can see the $t$-statistic of the daily return growth rate of the Comex gold future and the weight average daily return growth rate of 5 stocks are less than the $t$-statistic under the significance at $1 \%$ level, and the $P$ value is 0 , which means the null hypothesis should be rejected. Therefore, the JPS and Comex are stationary.

5.2. Granger Causality Test. Table 2 shows the result of the Granger causality test.

The $F$-statistic of the first line is significantly greater than the critical value of $F$ at $99 \%$ confidence level, and its $P$ value is a near-zero constant, so the null hypothesis that the price change of the international gold future does not guide the price change of the Chinese gold stocks is rejected. And the price change of the international gold future guides the price change of the Chinese gold stocks at $99 \%$ confidence level.

The $F$-statistic of the second line is less than the critical value at $99 \%$ confidence level and $P$ value is 0.5874 , which is 
TABLE 1: The result of the unit root test.

\begin{tabular}{lcc}
\hline ADF test statistic & $t$-statistic & $P$ value \\
\hline JPS & -25.5933 & 0.000 \\
Comex & -24.4506 & 0.000 \\
The critical value & & \\
$\quad 1 \%$ level & -2.5684 & \\
$5 \%$ level & -1.94129 & \\
$10 \%$ level & -1.61638 & \\
\hline
\end{tabular}

Note. JPS means the weight average daily return growth rate of 5 stocks. Comex means the daily return growth rate of the Comex gold future.

TABLE 2: The result of the Granger causality test.

\begin{tabular}{lcc}
\hline Null hypothesis & $F$-statistic & $P$ value \\
\hline Comex does not Granger cause JPS & 33.1689 & $1.80 E-14$ \\
JPS does not Granger cause Comex & 0.53249 & 0.58739 \\
\hline
\end{tabular}

Note. JPS means the weight average daily return growth rate of 5 stocks. Comex means the daily return growth rate of the Comex gold future.

TABLE 3: The selection of the VAR model optimal lag period.

\begin{tabular}{lcc}
\hline Period & AIC & SC \\
\hline 0 & -10.8977 & -10.7222 \\
1 & -10.8299 & -10.8164 \\
2 & $-10.91258^{*}$ & $-10.87208^{*}$ \\
3 & -10.9037 & -10.8361 \\
4 & -10.9086 & -10.8141 \\
\hline
\end{tabular}

Note. ${ }^{*}$ stands for the optimal period.

relatively great, so the null hypothesis that the price change of Chinese gold stocks does not guide the price change of international gold future should be accepted. The conclusion here is consistent with the findings of many scholars.

5.3. VAR Model. First, it is necessary to determine the lag period. Based on the smallest AIC and SC values, the lag period $P$ is the optimal lag period. According to Table 3, the smallest AIC and SC values appear when $P$ equals 2 . Therefore, we select $P=2$ as the optimal lag period.

Second, the stable test of the VAR. Using AR root table test method, we get the result (Table 4).

The test shows there is no root that lies outside the unit circle, so the VAR model meets the stability requirements. We get the matrix form of VAR model as follows:

$$
\begin{aligned}
\left(\begin{array}{c}
\mathrm{JPS} \\
\text { Comex }
\end{array}\right)= & \left(\begin{array}{cc}
-0.062 & 0.675 \\
0.016 & 0.6467
\end{array}\right)\left(\begin{array}{c}
\mathrm{JPS}_{t-1} \\
\mathrm{Comex}_{t-1}
\end{array}\right) \\
& +\left(\begin{array}{cc}
0.003 & -0.06 \\
0.013 & -0.055
\end{array}\right)\left(\begin{array}{c}
\mathrm{JPS}_{t-2} \\
\text { Comex }_{t-2}
\end{array}\right) \\
& +\left(\begin{array}{c}
-0.0002 \\
0.0006
\end{array}\right) .
\end{aligned}
$$

From the equation above, we can see that the coefficient of the stock lag term is rather small in the JPS equation, while the coefficient of gold future lag term is relatively great, which
TABLE 4: AR root.

\begin{tabular}{lc}
\hline Root & Modulus \\
\hline$-0.076204-0.200863 i$ & 0.214833 \\
$-0.076204+0.200863 i$ & 0.214833 \\
$0.069731-0.094652 i$ & 0.117564 \\
$0.069731+0.094652 i$ & 0.117564 \\
\hline
\end{tabular}

illustrates that the fluctuation of gold stocks in Shanghai and Shenzhen A-share is influenced by external price change more than themselves. In the gold future equation, its lag coefficient is significantly greater than that of the gold stock, but the coefficient is greater than the one in the JPS equation, which shows the Comex gold future is affected by stock price change to some degree. And this result is consistent with the conclusion of Granger causality test.

5.4. Impulse Response Function. Impulse response functions describe how the economy reacts over time to exogenous impulses, which economists usually call shocks, and are often modeled in the context of a VAR. In this paper, we use impulse response function to analyze the price volatility of gold stocks in Shanghai and Shenzhen stock and the international gold futures. Selecting 10 as the impulse function tracking period, we can conduct impulse analysis to the daily return growth rate of JPS and Comex from January 1, 2010, to December 31, 2012, and the results are shown as in Figure 1.

In Figure 1, abscissa indicates the follow-up period, the vertical axis represents the level of impulse response, Figure 1 shows Comex, the price of international gold futures, impact price fluctuations on their own in the first follow-up period are $1.14 \%$, the impact in the second follow-up period rapidly decreases to $0.1 \%$, it decreases to $0.1 \%$ below zero in the third follow-up period, and the impact gradually converges to 0 from the fourth follow-up period. The impact of the JPS on the international gold futures is 0 in the first follow-up period, the impact increases to $0.04 \%$ from the second follow-up period, the impact in the third follow-up period is almost the same to the second follow-up period, it is $0.03 \%$, and the impact starts converging to 0 in the fourth follow-up period.

From Figure 2, the impact of JPS on the price fluctuations on their own in the first follow-up period is $2.3 \%$, and it decreases to $1.4 \%$ below zero in the second follow-up period and then rises in third follow-up period to $0.02 \%$. And then it gradually converges to 0 in the fourth follow-up period. The impact of Comex on JPS is $6.3 \%$ in the first follow-up period, and then it increases to $7.2 \%$ in the second follow-up period. It decreases to $0.6 \%$ below zero in the third follow-up period, and then it decreases and gradually converges to 0 in the fourth follow-up period.

In summary, the effect of the price change of international gold futures on the price change of gold stocks in Shanghai and Shenzhen is obvious, and the guiding impact of the price change of the gold stocks to the international gold futures is not obvious. The impulse response efficiency of the international gold futures to gold stocks in Shanghai and Shenzhen stock surpasses the gold stocks in Shanghai and Shenzhen stock to international gold futures. This illustrates 


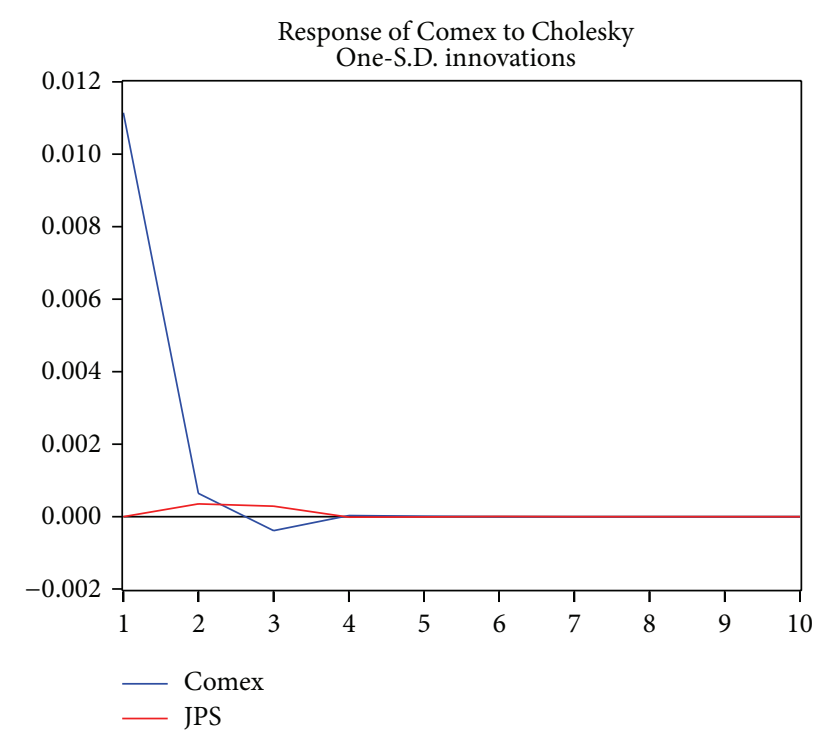

FIGURE 1: The impulse response function analysis graph of Comex.

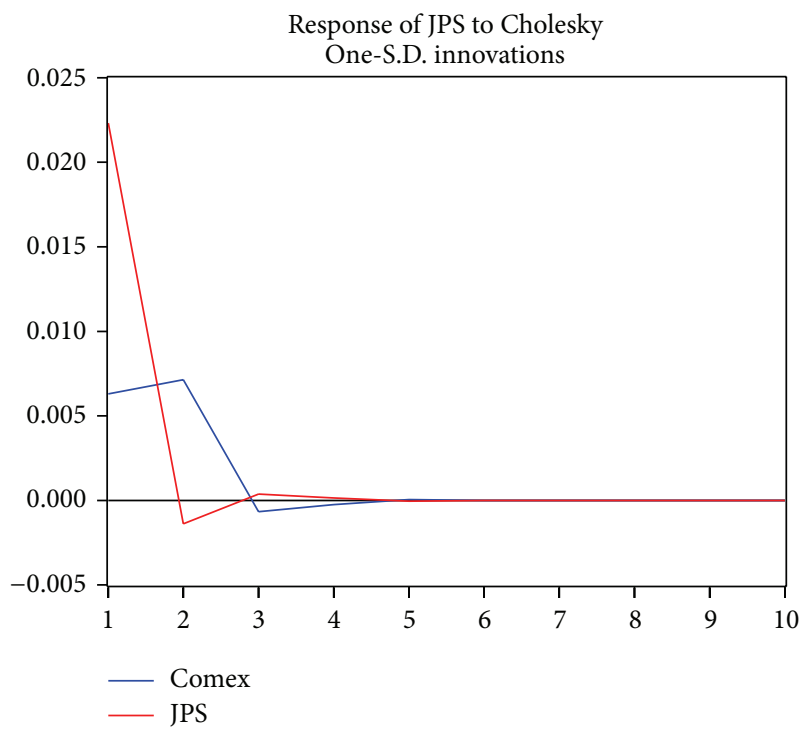

FIGURE 2: The impulse response function analysis graph of JPS.

the influence and authority of the international gold futures is much greater than the gold stocks in Shanghai and Shenzhen stocks. There is long-term equilibrium relationship between the foreign and domestic futures and spot, but the guiding force of the foreign futures and spot to domestic futures and spot is greater than that of the latter to the former.

\section{Conclusion}

Based on the empirical analysis above, we can get the main conclusions of this paper.

(1) As the foreign financial market will bring about the fluctuations to the domestic market price, it is necessary to examine the impact that international market price movements have on the domestic market.

(2) Granger causality test shows the price change of the international gold futures is the reason which causes the price change of the gold stocks in Shanghai and Shenzhen A-share, but in the reverse situation it is much less. It illustrates the international gold futures have an unidirectional guiding role on the gold stocks in Shanghai and Shenzhen A-share. By impulse response function, we can further clearly understand that the fluctuation of the foreign gold futures and spot has much stronger effect on the domestic market. It suggests we must continue to foster our markets both stocks, futures, and spot.

\section{Conflict of Interests}

The authors declare that they have no conflict of interests.

\section{Acknowledgments}

This research was supported by the National Natural Science Foundation of China (Grant no. 71171176) and the Program of Humanities and Social Sciences of Ministry of Education of China (Grant no. 12YJC910011).

\section{References}

[1] X. Jiaming, "The empirical study of the China and America gold futures market efficiency," Journal of Shanghai Commercial College, vol. 9, no. 5, pp. 18-24, 2009.

[2] F. Wen, X. Cong, Y. Chao, and X. Chen, "The effects of prior outcomes on risky choice: evidence from the stock market," Mathmatical Problems in Engineering, vol. 2014, Article ID 272518, 8 pages, 2014.

[3] F. Wen and Z. Liu, "A copula-based correlation measure and its application in chinese stock market," International Journal of Information Technology and Decision Making, vol. 8, no. 4, pp. 787-801, 2009.

[4] T. Zhipeng and Z. Guoyan, "The empirical study of the price relation of Chinese gold market futures and spot," Journal of Shandong Institute of Business, vol. 23, no. 2, pp. 76-81, 2009.

[5] W. Di and H. Jiangming, "The study of the impact that the price volatility of New York gold futures price on China futures market yield," Economic Survey, vol. 2, no. 2, pp. 22-27, 2010.

[6] F. Wen, Z. He, X. Gong, and A. Liu, "Investors' risk preference characteristics based on different reference point," Discrete Dynamics in Nature and Society, vol. 2014, Article ID 158386, 9 pages, 2014.

[7] F. Wen, Z. He, and X. Chen, "Investors' risk preference characteristics and conditional skewness," Mathmatical Problems in Engineering, vol. 2014, Article ID 814965, 14 pages, 2014.

[8] F. Wen and X. Yang, "Skewness of return distribution and coefficient of risk premium," Journal of Systems Science \& Complexity, vol. 22, no. 3, pp. 360-371, 2009.

[9] H. A. Shawky, A. Marathe, and C. L. Barrett, "A first look at the empirical relation between spot and futures electricity prices in the United States," Journal of Futures Markets, vol. 23, no. 10, pp. 931-955, 2003. 
[10] B. M. Lucey and E. Tully, "Seasonality, risk and return in daily COMEX gold and silver data 1982-2002," Applied Financial Economics, vol. 16, no. 4, pp. 319-333, 2006.

[11] D. Hillier, P. Draper, and R. Faff, "Do precious metals shine? An investment perspective," Financial Analysts Journal, vol. 62, no. 2, pp. 98-106, 2006.

[12] H.-N. Lin, S.-M. Chiang, and K.-H. Chen, "The dynamic relationships between gold futures markets: evidence from COMEX and TOCOM," Applied Financial Economics Letters, vol. 4, no. 1, pp. 19-24, 2008.

[13] P. D. Cretien, "Gold \& silver: always good options," Futures: News, Analysis \& Strategies for Futures, Options, Derivative Traders, vol. 40, no. 5, pp. 28-30, 2011.

[14] W.-C. Lee and H.-N. Lin, “Threshold effects in the relationships between USD and gold futures by panel smooth transition approach," Applied Economics Letters, vol. 19, no. 11, pp. 10651070, 2012. 


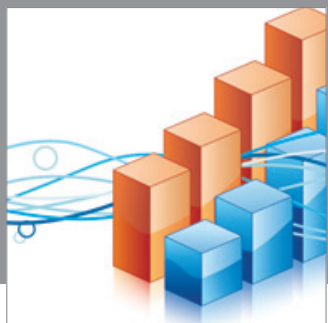

Advances in

Operations Research

mansans

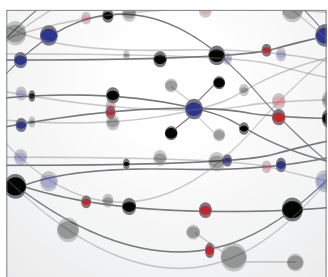

The Scientific World Journal
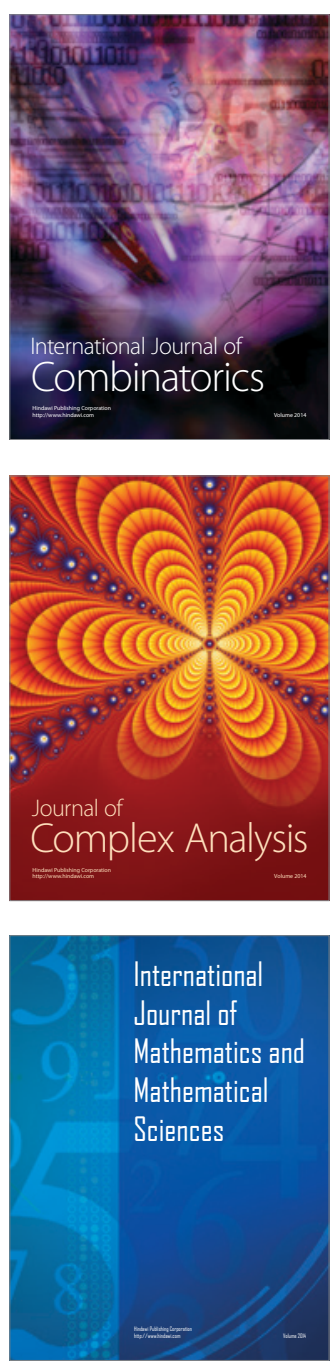
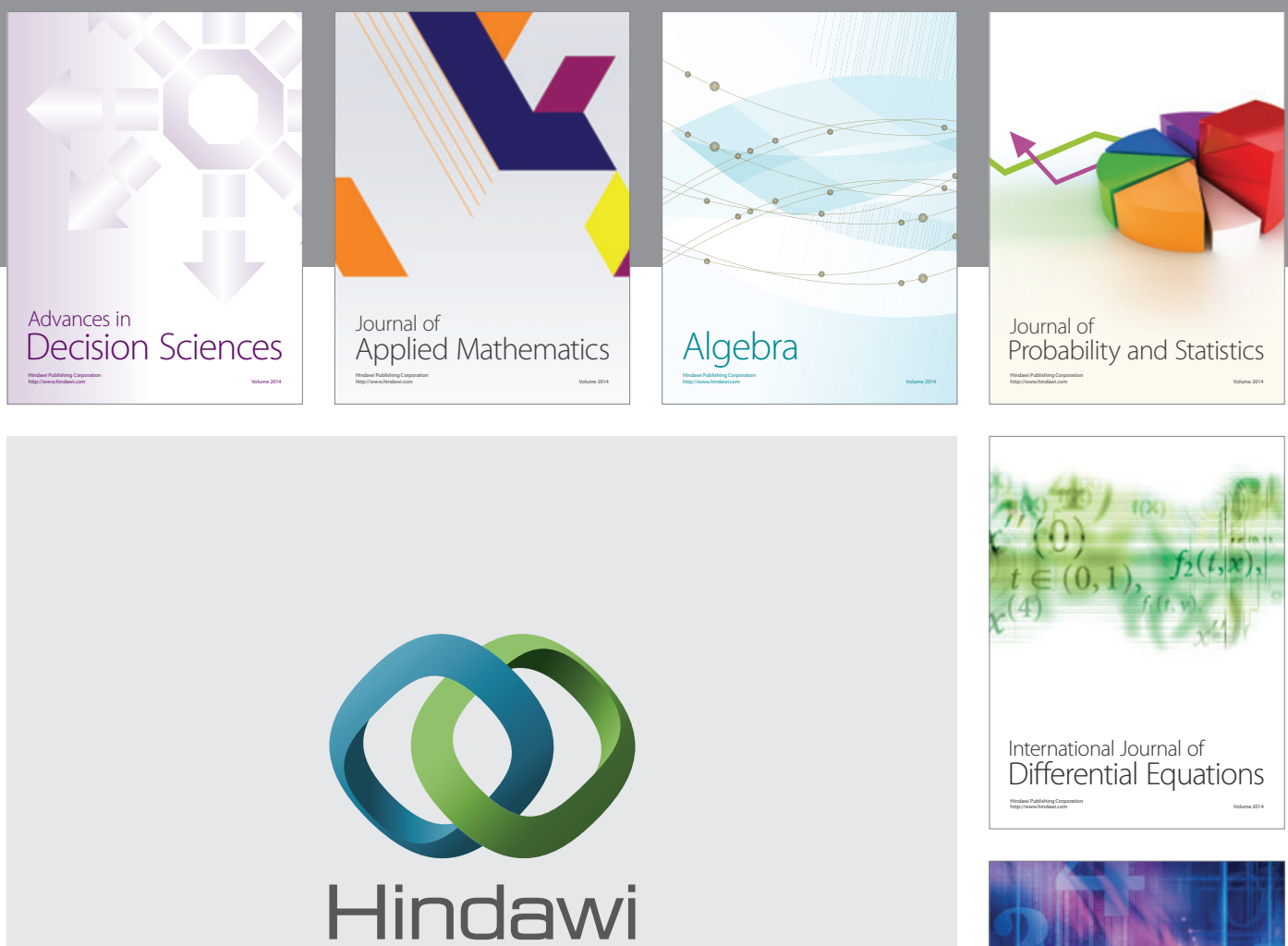

Submit your manuscripts at http://www.hindawi.com
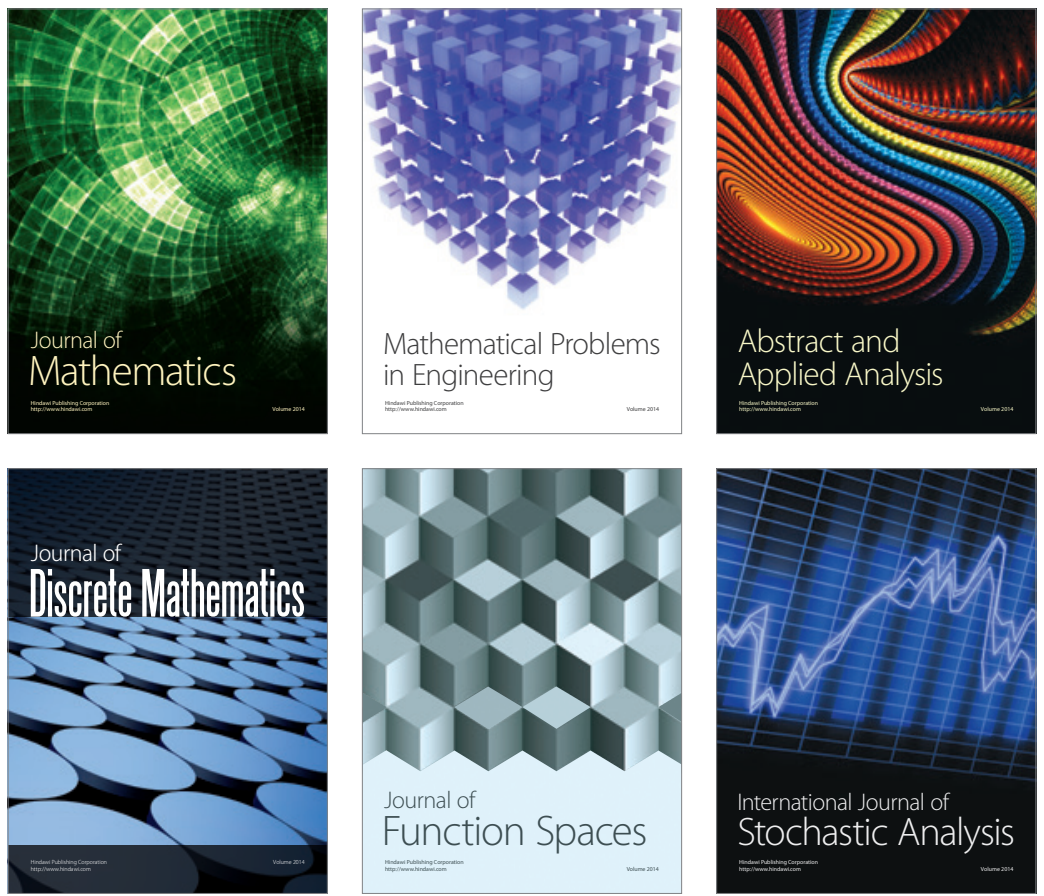

Journal of

Function Spaces

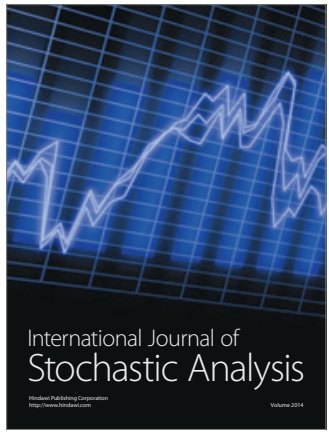

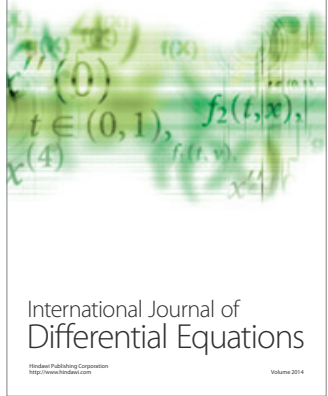
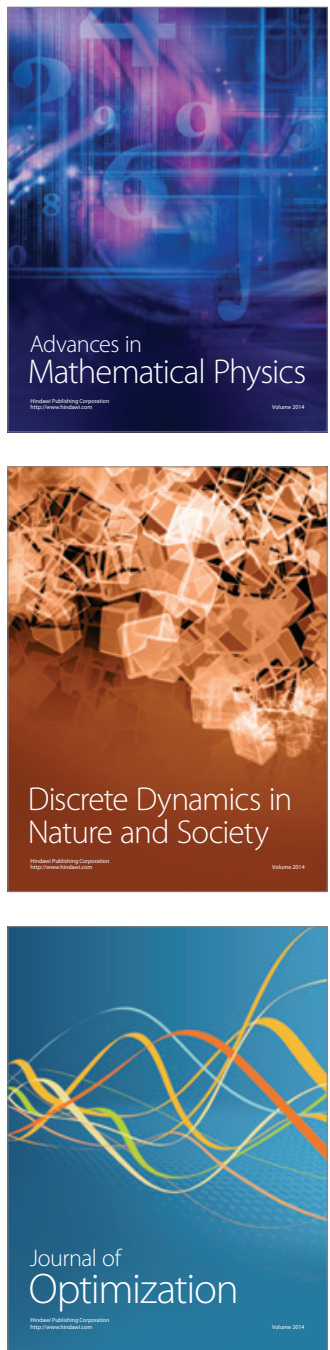